Research Article

\title{
Environmental Impact Analysis of Hub-and-Spoke Network Operation
}

\author{
Yong Tian $\mathbb{D}^{1},{ }^{1}$ Mengyuan Sun, ${ }^{1}$ Lili Wan ${ }^{D},{ }^{1}$ and Xu Hang ${ }^{2}$ \\ ${ }^{1}$ College of Civil Aviation, Nanjing University of Aeronautics and Astronautics, Nanjing 210016, China \\ ${ }^{2}$ Central South Air Traffic Management Bureau of Civil Aviation Administration of China, Guangzhou 510406, China
}

Correspondence should be addressed to Yong Tian; tianyong@nuaa.edu.cn

Received 31 January 2020; Revised 26 March 2020; Accepted 30 March 2020; Published 21 April 2020

Academic Editor: Stefan Balint

Copyright (c) 2020 Yong Tian et al. This is an open access article distributed under the Creative Commons Attribution License, which permits unrestricted use, distribution, and reproduction in any medium, provided the original work is properly cited.

The hub-and-spoke network has demonstrated its economies of scale and scope in the rapid development of the civil aviation industry. In order to fit the development trend of green civil aviation, a series of environmental problems such as fuel consumption and pollutant emissions caused by air transportation cannot be ignored. Firstly, this paper selects six cities of Shenyang, Beijing, Qingdao, Zhengzhou, Guangzhou, and Nanjing as the research objects, collects the passenger flow and the distance information of the corresponding segment, determines the location of the hub airport, analyzes the operating environment of the aircraft in the hub-and-spoke network, establishes an aircraft emission assessment model, and calculates the mass of aircraft emissions and fuel consumption. Secondly, based on the calculation results, the comparison of aircraft emissions and fuel consumption between the hub-and-spoke network and the point-to-point network shows that the total carbon monoxide (CO) emissions are reduced by $35.84 \%$, the total hydrocarbon compounds $(\mathrm{HC})$ emissions are increased by $68.82 \%$, and the total nitrogen oxides $\left(\mathrm{NO}_{\mathrm{x}}\right)$ emissions are increased by $24.87 \%$. The total mass of pollutants (including $\mathrm{CO}, \mathrm{HC}$, and $\mathrm{NO}_{\mathrm{x}}$ ) decreased by $29.37 \%$, and the total fuel consumption decreased by $68.17 \%$. In general, the use of a hub-and-spoke network reduces the pollutant emissions and fuel consumption of aircraft as a whole while ensuring the lowest passenger transportation cost. Finally, based on the current international situation and the enhancement of people's awareness of environmental protection, a summary analysis of the huband-spoke network and the point-to-point network is obtained, and some enlightenment and research significance are obtained.

\section{Introduction}

Air transportation has grown rapidly with an average annual growth rate of $4.5 \%$ to $5 \%$ [1], which is the fastest growing among all modes of transportation. In order to comply with the development trend of green civil aviation, a series of environmental problems such as fuel consumption and pollutant emissions caused by aircraft operations cannot be neglected. According to relevant reports, greenhouse gas emissions from air transportation are increasing at a rate of $3.6 \%$ per year [2], and the aviation market is facing increasing fuel costs [3]. According to the International Air Transport Association (IATA) report, global aviation fuel expenditure in 2018 is about $\$ 180$ billion, an increase of $20.5 \%$ over 2017 [4].

Aviation emissions and fuel consumption have also aroused widespread concern. Reference [5], through a living project, developed an inventory of air pollutants (CO, VOC, $\mathrm{NO}_{\mathrm{x}}$, and PM10) for the Campania region. The inventory clarified the spatial distribution of all emission sources, classified these pollutants, and analyzed the results by drawing a map set of the area. In the same year, through the LIFE project with environmental characteristics, literature [6] used a Gaussian diffusion model to conduct a local-scale assessment of air quality conditions and estimated the main air pollutants concentrations in Campania. Combining previous research, Iodice and Senatorel [7] used a bottom-up approach to evaluate and calculate the total emissions of major pollutants (including $\mathrm{CO}, \mathrm{VOC}, \mathrm{NO}_{\mathrm{x}}, \mathrm{PM} 10$ ) in Campania. Where possible, direct and continuous measurements were used, and for other diffusion sources, emissions were estimated based on appropriate activity indicators and emission factors. Took road traffic as an 
example to analyze the case and proposed that the use of corresponding new technologies and cleaner gaseous fuels in the future would replace the use of gasoline, thereby reducing $\mathrm{CO}$ and $\mathrm{HC}$ emissions. It is well known that emission inventories and biological monitoring are two different methods for assessing air pollution. Reference [8] combined emission inventory and biological monitoring methods of moss transplantation to compare and analyze $\mathrm{CO}, \mathrm{NO}_{\mathrm{x}}$, PM10, $\mathrm{VOC}_{s}$, heavy metals, and other pollutants in five cities in southern Italy, providing a reference role for future air pollution monitoring issues. Carslaw et al. [9] proposed graphic technology of bivariate polar coordinates and data filtering technology aimed at detecting and quantifying the contribution of the airport to the $\mathrm{NO}_{\mathrm{x}}$ concentration in a network of seven measurement points near the airport, the contribution of the airport's long-term average concentrations of $\mathrm{NO}_{\mathrm{x}}$ and $\mathrm{NO}_{2}$ was evaluated. Literature [10] used population density and disease statistics, aircraft emissions inventories, global chemical transport models, and epidemiological studies to study premature deaths caused by global aircraft emissions (including take-off, cruise, and descent phases). The study also found that NOx emissions from aircraft would increase the oxidation of nonaircraft $\mathrm{SO}_{2}$, which would cause aviation to have a greater impact on air quality. Reference [11] uses a simplified approach to assess the benefits of reduced aviation fuel combustion, including those related to air quality and climate. In fact, the world 's energy needs are increasing and reducing aviation emissions, and fuel consumption is becoming more and more critical. Accurate assessment of aircraft fuel consumption will help improve airlines' safety and profitability. Effective control of fuel consumption is an important concern for airline operating organizations. Reference [12] proposed an improved method based on the estimation of fleet fuel consumption and engine cleaning costs and optimized the interval of fleet engine cleaning, which was beneficial to reducing fuel consumption and aviation emissions. Reference [13] proposed a novel self-organizing neural network algorithm with a cascade topology that could analyze and calculate the connection weight coefficients to estimate the fuel for each flight. This helped airlines accurately plan the amount of fuel for the flight itinerary, avoided loading extra fuel on the aircraft, reduced aircraft fuel consumption, and increased engine life. Reference [14] proposed an improved $K$-means clustering method for aircraft descent phase. An example analysis showed that the relationship between fuel consumption and flight altitude, weight, and actual speed during the descent of the aircraft was a certain one. This method aimed to reduce the fuel consumption of the aircraft during the descent phase, thereby reducing the greenhouse gas emissions of the aircraft in the city and playing a role in the development of green aviation. In response to the current situation, the governments, aviation authorities, and companies have introduced appropriate environmental policies and measures to encourage airlines to become more environmentally friendly [15]. The airline network is the foundation of the airlines, which stipulates the service scope and service scale of the airlines, which reflects the competitiveness of airlines, operating costs, and service level. The design of the airline network is related to the sustainable development of airlines. Further, with the rapid development of the civil aviation transportation market in China, the scale of the airline network is gradually expanding, and the competition is becoming more and more fierce. The point-to-point network originally adapted to the small-scale transportation market may not be suitable for the further development of China's civil aviation industry. And the hub-and-spoke network is an airline network structure in which the air transportation market reaches a certain scale and can fully reflect the economies of scale. The in-depth study of the environmental impact in the hub-and-spoke network can provide corresponding assistance decisions for airlines, and then this research will provide airlines with certain guiding and reference role.

As we all know, there are exhaust emissions from an aircraft which are $\mathrm{NO}_{\mathrm{x}}, \mathrm{CO}$, water vapour $\left(\mathrm{H}_{2} \mathrm{O}\right), \mathrm{CO}_{2}$, and other gases and particles. Aircraft engines make such emissions in the atmosphere. From an environmental perspective, the emission is a significant impact of aircraft. Understanding the type and amount of aircraft emissions is becoming increasingly important not only for environmental reasons but also for health reasons. U.S. Environmental Protection Agency (EPA) calls $\mathrm{NO}_{\mathrm{x}}, \mathrm{HC}$, and $\mathrm{CO}$ "standard pollutants." $\mathrm{HC}$ is a complex and diverse organic compound, which contains a small number of aldehydes and a small number of aromatic hydrocarbons. The combined action of the above substances will have a stimulating effect on the mucous membranes of the human nose, eyes, and respiratory tract, causing conjunctivitis and rhinitis. $\mathrm{NO}$ and $\mathrm{NO}_{2}$ together form $\mathrm{NO}_{\mathrm{x}}$. The three compounds are related to each other and change from one form to another through chemical reactions. $\mathrm{NO}_{2}$ can cause respiratory diseases at high concentrations and threaten human health. $\mathrm{CO}$ is the product of insufficient combustion of fuel, which can react with haemoglobin, reducing the blood's ability to carry oxygen. Higher CO concentrations can cause considerable harm to the cardiovascular and central nervous systems. During the operation of the airline network, although the pollutants emitted by the aircraft will not have a rapid impact on the surrounding environment, due to the cumulative effect and the long-term continuous discharge of pollutants, it will inevitably increase the negative impact and cause chronic diseases. In the context of the rapid development of the air transport industry, increasing fuel prices and current environmental policies urgently require efficient fuel use and environmentally friendly aircraft operations.

This paper is primarily concerned with air passenger networks connecting environmental impact analysis of the hub-and-spoke network. Within the required number of a hub airport, passenger flow, and segment distance, the arrangement of the hub-and-spoke network is obtained. In order to analyze effectively the environmental impact of hub-and-spoke network, this paper introduces a point-topoint network for comparative analysis. In a point-to-point network, there are some issues: long-haul flows allow larger aircraft, and larger flows could request for multiple aircraft. Long-haul aircraft need more fuel and generate more 
harmful gases. There are potentially lower operating costs when flows are handled by certain types of infrastructure (wide-body or more seats aircraft). In a hub-and-spoke network, there are numerous origin-destination (OD) pairs, and each OD pair has three components: collection (from origin node to a hub node), transfer (between hub nodes), and distribution (from hub node to destination node). Thus, providers of transportation services may reduce transportation costs by concentrating passengers between hubs for transfer, which reflects economies of scale. There are large-size aircraft with a large number of seats between the hubs for transfer component, medium-size aircraft with a moderate number of seats between nonhub and hub for collection and distribution components.

This research begins to analyze the environmental impact of hub-and-spoke, compared with the point-to-point network. The remainder of the paper is organized as follows: In Section 1, a literature review of relevant literature is conducted. Section 2 describes the mathematical formulations pertaining to hub airport location and aircraft emission. In Section 3, we select six cities with typical representatives for case analysis, determine the location of the hub airport and comparative analysis of the pollutant emissions of the hub-and-spoke network, and the point-topoint network. Finally, Section 4 gives a short summary and suggested topics for future research in this research.

\section{Literature View}

The construction of the hub-and-spoke network is a complex issue involving many factors. The location of the hub airport is one of the key steps. Giovanni [16] explored the productive efficiency and profitability of the large hub-and-spoke network. The vital assumption was that the hub was infinite. The result of the paper was that larger hub-and-spoke network provides cost benefits, which rendered into heavier traffic and lower fares through the network. Ebery et al. [17] proposed formula and algorithm based on the capacity allocation of multiobjective hub location assignment, which laid a theoretical foundation for the hub location problem. Campbell and O'Kelly [18] emphasized the need to go beyond the classical model to define new models to better solve the problem of hub location in actual scenarios. Contreras [19] introduced the basic concept of the location of the hub and the steps of the site selection of the hub, combined with examples to determine the specific location of the hub airport. They then had a comprehensive understanding of the location problem of the hub airport. Gao and Qin [20] used travel time as an uncertain variable to model and analyze the p-hub center problem based on an expert scoring method in the absence of large amounts of data. Akgün and Tansel [21] had adopted a new way to define the p-hub median problem of incomplete networks based on real roads and railways, without applying the shortest path method or not satisfying the triangle inequality. Ghaffarinasab et al. [22] developed the simulated annealing algorithm to find the optimal solution of the hub location problem in the case of single allocation and multiple allocations. A large number of calculation results showed that the algorithm can obtain the optimal solution in a short time. Amin-Naseri et al. [23] have taken into account the maximum uncertainty in the network and the total transportation cost and studied the singledistribution p-hub median problem under the condition of no capacity limitation. Števárová et al. [24] used the characteristics of an efficient connection method in which a single hub airport could simultaneously connect multiple origins and multiple destinations and considered the connectivity between hubs to undertake the performance of the hub-and-spoke network. Soylu and Katip [25] used the Variable Neighborhood Search (VNS) algorithm to find the Pareto optimal solution with the lowest transportation cost and transit number in the airline network and solved the problem of multiobjective hub airport location in the airline network design.

In recent years, aviation emissions have become an important social issue. According to data from the International Air Transport Association (IATA), aviation emissions account for about 2\% [26] of anthropogenic carbon emissions. Under the trend of rapid growth in aviation emissions, environmental problems will become more serious without any emission reduction measures. Therefore, the development of green civil aviation is imminent, and studying the operating environment of the airline network is of great significance for the development of green civil aviation.

Peter and Lu [27] constructed the environmental impact model of a hub to hub and hub by-pass flight networks, which included five cases for the evaluation of engine emissions social cost for the two scenarios. It was shown that the emissions social cost's impact of the hub to hub networks was obviously higher than the hub by-pass in all cases. Kim et al. [28] described the algorithms and data used in the System for assessing Aviation's Global Emissions (SAGE), which included emissions module, flight data processor module, aircraft performance module, and so on. SAGE was used to evaluate the trends of fuel consumption and emissions. Zachary et al. [29] established a multiobjective optimization model based on the aircraft's track, speed, fleet composition, and operating conditions and used integer programming to solve the environmental problems of minimum noise impact and aviation emissions. Prats et al. [30] designed a multiobjective optimization strategy for the noise reduction process considering factors such as the takeoff flight trajectory, fuel consumption, and time cost of the aircraft. Alumur et al. [31] resolved travel costs in the actual hub airline network to study the location of the hub. Morton [32] used a knapsack model to minimize fuel burn on the condition of no resource constraints of aircraft. By establishing a model for hub-and-spoke discounts: a new model for link flow and fuel costs, the paper indicated that an allocation hub-and-spoke model can be amalgamated to a single assignment flow model and a small increase in fuel consumption. Kesgin [33] dealt 40 Turkish airports to estimating aircraft landing and take-off (LTO) emissions (HC, $\mathrm{CO}, \mathrm{NO}_{\mathrm{x}}$ ). Taking into account factors such as aircraft emissions and fuel consumption, Khoo and Teoh [34] quantified green performance indicators of the airline companies by deriving the Green Fleet Index (GFI) and 
established a biobjective stochastic dynamic programming model to minimize GFI and maximize profits and obtained the optimal aircraft fleet composition. Kim et al. [35] combined with the minimum separation interval, aircraft priority order, operation path, and other factors to allocate the runway usage of the aircraft of the arrival and departure flights on the runway, so that the total emissions generated by the terminal area and the scene operation were minimized. Based on the input flight plan data (including operation, technology, and cost parameters, etc.), Rosskopf et al. [36] studied the balance between airline transportation cost and aircraft $\mathrm{NO}_{\mathrm{x}}$ emissions in the long-term fleet plan and found the Pareto optimal solution by changing the weight. Ho-Huu et al. [37] have optimized the aircraft's takeoff trajectory with the goal of minimizing fuel consumption and noise pollution. Müller et al. [38] formulated a method of optimizing the aircraft fleet composition of airlines by using the emission threshold method. Focusing on energy conservation and emission reduction, based on the actual operational data of the two major European airlines, the operation of the airline from 2016 to 2025 was planned. Optimization programs were important for achieving shortterm emissions targets.

The above research shows that the rapid development of air transportation has brought convenience to people but also caused certain environmental impacts and may even be harmful to human health. Therefore, green civil aviation has become a major trend in the development of the air transport industry. In the "Thirteenth Five-Year Plan for Civil Aviation Administration of China," it is proposed to "establish the energy conservation and emission reduction regulations system of the civil aviation industry and improve a regulatory mechanism for energy conservation and emission reduction in the industry" to comply with the social trends of sustainable green development.

\section{Environmental Impact of Hub-And-Spoke Network Operation}

The hub-and-spoke network has optimized airline layout, allocated resources appropriately, and enhanced the competitiveness of airlines. At the same time, it can also promote the development of the airport economy and the prosperity of the city. In order to comply with the development trend of the green air transport industry, the environmental impact of aircraft in the operation of the hub-and-spoke network cannot be overlooked.

In this section, this paper constructs a hub-and-spoke network. The number of hub airports is given in advance, there is no capacity limitation on the airports and airline, and certain assumptions are met. Considering the above conditions, a problem of uncapacitated multiple allocation p-hub median problems is formed, which is dealt with by proposing an integer linear programming model. For aircraft emissions, this research introduced the aircraft emission assessment model to calculate the pollutant emissions $\left(\mathrm{NO}_{\mathrm{x}}, \mathrm{HC}, \mathrm{CO}\right)$ and fuel consumption of the aircraft to facilitate analysis of the operating environmental impact of the airline network.
3.1. Problem Statement. To build a hub-and-spoke network between cities and analyze its environmental impact, an airline needs to determine the location of the hub airport and the airline allocation between hub airport and nonhub airport and calculate the aircraft emissions and fuel consumption of the hub-andspoke network and the point-to-point network by establishing an aircraft emissions assessment model. Given a complete graph $G=(N, A)$, which refers to a collection of nodes and the edges of the connected nodes. $N=\{1,2, \ldots, n\}$ denotes the set of nodes, which corresponds to origins or destinations in a network. ' $n$ ' is the number of nodes in the network. $A=\left\{a_{i j}(i, j) a_{i j}(i, j) \mid i \neq j, i, j \in N\right\}$ stands for the set of edges.

As shown in Figure 1, in the hub-and-spoke network, nodes are cities, and edges stand for the airline allocation. There is a passenger flow demand of $Q_{i j}$ from node $i$ to node $j$. $Q_{i j}$ is the volume of the associated passengers flow, and $Q_{i j}=Q_{j i}, Q_{i i}=0$, that shows the network is a nondirectional network. We consider $C_{i j}$ as the transportation cost per unit flow from node $i$ to node $j$. $C_{i j}$ is proportional to the $\mathrm{Eu}$ clidian distance associated with each ordered pair of nodes and $C_{\text {aa }}=0, C_{i j} \geq 0, \forall i, j \in N$.

In collection component, the hub-and-spoke network concentrates less-traffic flights to hub nodes and redistributes them through hub nodes in transfer and distribution components to achieve economies of scale in transportation. Therefore, each component has its own unit discount coefficients of $\chi \alpha, \delta$. Of course, not all passenger flows will go through these three components, and some will only experience some of them. Thus, the unit flow collection cost under certain scenarios is $\chi C_{i k}$, where $i$ refers to a nonhub node and $k$ stands for a hub node. Analogously, the transfer has a cost $\alpha C_{\mathrm{km}}$, where $k$ and $m$ are also both hub nodes. Distribution has a cost of $\delta C_{m j}$, where $m$ indicates a hub node and $j$ denotes a nonhub node. Referring to the classification for aircraft [39], a large-size aircraft with a large number of seats and a medium-size aircraft with a moderate number of seats is selected as available aircraft type.

\subsection{Mathematical Formulations}

3.2.1. Hub Airport Location. The hub-and-spoke network has greatly adapted to the development of the air transport industry with its flexible, convenient, and large coverage features. The economical and expedient airline network structure further strengthens its core competitiveness. Therefore, in the hub-and-spoke network, the specific transportation path is arranged for all OD flows with the minimum total transportation cost as the objective function.

In order to formulate our model, we mainly use the mathematical formulation for the model presented by Ebery et al. [17]. Our objective function is as follows:

$$
\min \sum_{i=1}^{n} \sum_{j=1}^{n} \sum_{k=1}^{n} \sum_{m=1}^{n} Q_{i j} C_{i j k m} x_{i j k m}
$$

where $i$ and $j$ denote nodes, $k$ and $m$ are hub nodes, $e$ is a path (i, $j, k, m)$ from the node $i$ to node $j$, passing through the hub nodes $k$ and $m$. The transportation cost of the unit passenger flow from node $i$ to node $j$ on this path, indicating $C_{i j k m}$, is 


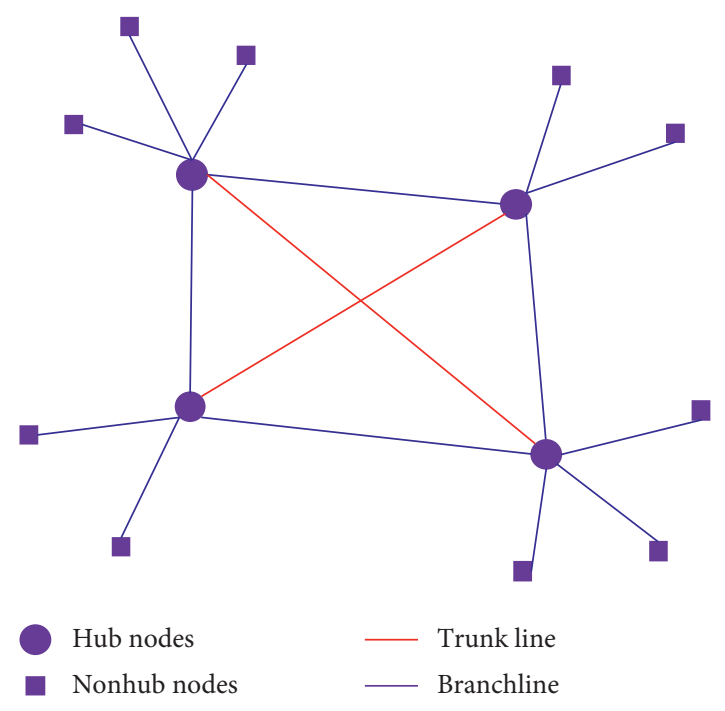

Figure 1: Hub-and-spoke network. The purple circles represent hub nodes and purple squares represent nonhub nodes. The thick red line indicates the trunk line, and the thin blue line indicates the branch line.

$C_{i j k m}=\chi C_{i k}+\alpha C_{k m}+\delta C_{m j} . x_{i j k m}$ represents the fraction of the passenger flow from node $i$ to node $j$ on the path $(i, j, k, m)$ via hubs located at $k$ and $m$ and $x_{i j k m} \geq 0 . \chi, \alpha$ and $\delta$ are the factors for the collection, transfer, and distribution, respectively.

In order to ensure that the solutions obtained are feasible, we introduce the following constraints:

(1) Hub number constraint

$$
\sum_{k=1}^{n} h_{k}=p
$$

where $p$ denotes the number of nodes to be selected as hub airports. Since the number of hub airports is given in advance, this paper considers the number of hub airports as $p . h_{k}$ is decision variables which are defined as follows:

$$
h_{k}= \begin{cases}1, & \text { if node } \mathrm{k} \text { is a hub } \\ 0, & \text { otherwise }\end{cases}
$$

(2) OD flow constraint

$$
\sum_{k=1}^{n} \sum_{m=1}^{n} x i_{j k m}=1, \quad i, j=1, \ldots n .
$$

Each pair of OD flow $Q_{i j}$ is transferred from node $i$ to node $j$ through hubs $k$ and/or $m$.

(3) Transfer constraints

$$
\begin{aligned}
& \sum_{m=1}^{n} x_{i j k m} \leq h_{k}, \quad i, j, k=1, \ldots, n, \\
& \sum_{k=1}^{n} x_{i j k m} \leq h_{m}, \quad i, j, k=1, \ldots, n,
\end{aligned}
$$

where $h_{k}$ and $h_{m}$ are decision variables. We consider that in the operation of the hub-and-spoke network, all OD flows can only be transferred via hubs.

(4) Special constraints

$$
\begin{aligned}
& \sum_{m=1}^{n} \sum_{k=1, k \neq i}^{n} x_{i j k m}+h_{i} \leq 1, \quad i, j=1, \ldots n, \\
& \sum_{m=1}^{n} \sum_{m=1, m \neq i}^{n} x_{i j k m}+h_{j} \leq 1, \quad i, j=1, \ldots n,
\end{aligned}
$$

Considering the special circumstances that may occur, when there is only one hub airport between the origin and the destination of the OD flow and the transfer is required, it can only be transferred at most once. If both the origin and the destination are hubs, only direct transport can be used.

3.2.2. Aircraft Emission Assessment Model. Under the rapid development of the civil aviation industry, the traffic volume has increased significantly, and environmental problems such as pollutant emissions and greenhouse effects cannot be ignored. In order to comply with the development trend of "green civil aviation," we analyzed the environmental impact of pollutant emissions and fuel consumption on the huband-spoke network. In this paper, we consider the harmful gas and select $\mathrm{CO}, \mathrm{HC}$, and $\mathrm{NO}_{\mathrm{x}}$ as pollutants, because there are clear guidelines related to the emissions of these species [40]. We establish an aircraft emission assessment model to calculate the pollution emissions of the hub-and-spoke network and the point-to-point network and get some thoughts and discussions.

According to the Federal Aviation Administration (FAA) officially recognized Aviation Environmental Design Tool (AEDT) for aircraft emissions and gas diffusion, aircraft emissions are related to operating time, fuel flow, engine quantity, emission index, and other parameters. Based on the above introduction, the aircraft emission assessment model is established [41], and the specific calculation for the total pollution of aircraft pollution is shown in equation (9):

$$
E_{p}=\sum_{r} \mathrm{TIME}_{r} \cdot \mathrm{EG}_{r} \cdot \mathrm{FF}_{r} \cdot \mathrm{EI}_{r, p}
$$

where $E_{p}$ indicates the emission of pollutant $p(\mathrm{~kg})$; $\mathrm{TIME}_{r}$ denotes an operational time for aircraft type $r(s) ; \mathrm{EG}_{r}$ is the number of engines of aircraft type $r ; \mathrm{FF}_{r}$ is the fuel flow for aircraft type $r$ with a single-engine during the time $\mathrm{TIME}_{r} ; \mathrm{EI}_{r, p}$ is emission index for aircraft type $r$ of pollutant $p(\mathrm{~kg} / \mathrm{kg})$. The emission index is defined as the mass of pollutants emitted per unit mass of fuel burned by a particular engine.

According to the performance parameters of each aircraft type in the Base of Aircraft Data (BADA) [42], the fuel flow rate of the aircraft is further calculated and expressed as equations (10)-(12): 


$$
\begin{aligned}
& \mathrm{FF}_{C}=C_{f_{1}} \cdot\left(1+\frac{V_{T}}{C_{f_{2}}}\right) \cdot F, \\
& \mathrm{FF}_{D}=C_{f_{3}} \cdot\left(1-\frac{h}{C_{f_{4}}}\right), \\
& \mathrm{FF}_{L}=C_{f_{1}}\left(1+\frac{V_{T}}{C_{f_{4}}}\right) \cdot C_{f_{r}} \cdot F,
\end{aligned}
$$

where $C_{f 1}$ (in $\mathrm{kg} /(\mathrm{min} \cdot \mathrm{kN})$ (jet)) is the 1st thrust specific fuel consumption coefficient, $C_{f 2}$ (in knots) is the 2nd thrust specific fuel consumption coefficient, $C_{f 3}$ (in $\mathrm{kg} / \mathrm{min}$ ) is the 1 st descent fuel flow coefficient, $C_{f 4}$ (in feet) is the 2 nd descent fuel flow coefficient, and $C_{f r}$ (in dimensionless) is cruise fuel flow correction coefficient. These can all be obtained from the BADA database. $F$ (in $k N$ ) is engine thrust; $V_{T}$ (in $k t$ ) is true airspeed; $h$ (in feet) is transition altitude for calculation of descent thrust. Equation (10) represents the fuel flow of the climbing segment; equations (11) and (12) represent the fuel flow of the descending and cruise segments, respectively. In equation (9), the value of $\mathrm{FF}_{r}$ can take the values $\mathrm{FF}_{C}, \mathrm{FF}_{D}$, and $\mathrm{FF}_{L}$ in equations (10)-(12).

\section{Numerical Case Study}

In order to describe the problem model, the actual problem is considered and the following assumptions are made [19]:

(1) The hub nodes are fully connected, nonhub nodes are not directly connected, and a hub node can be connected to multiple nonhub nodes; that is, multiple distribution connections are used. Considering the economies of scale of transfer between hub nodes, we assume $\alpha<1, \chi=\delta=1$ [43].

(2) Considering that the service object of this paper is passengers, any OD flow can be transited through at most two hub airports.

(3) All OD flows must be conveyed from the origin to the destination and the transfer should only be through the hub airport.

(4) The cost of setting the connecting edge between the hubs is 0 ; that is, regardless of the cost of opening the airline, there is no additional cost to ensure connectivity with the hub.

(5) For the same city pair, the traffic flow at the opposite of the origin and the destination is the same.

4.1. Determine the Location of the Hub Airport. Shenyang is located in Northeast China and central Liaoning. It is located in the center of the Northeast Asian Economic Circle and the Bohai Rim Economic Circle. It is the geographic center of Northeast Asia. The "Belt and Road" is an important node that extends to Northeast Asia and Southeast Asia. Beijing is the capital of the People's Republic of China and one of the four municipalities directly under the Central Government of China; Beijing is a national central city, a mega city, a national political center, a cultural center, an international communication center, and a science and technology innovation center. Qingdao, an important national coastal city and an international port city approved by the State Council, is also the economic center of Shandong Province, a coastal resort city, a national leading area for the development of modern marine industries, an international shipping hub in Northeast Asia, and a base of marine sports. The main nodes of the New Asia-Europe Continental Bridge Economic Corridor and strategic fulcrum of maritime cooperation. Zhengzhou is an important central city in central China, a mega city, an important national comprehensive transportation hub, a commerce and logistics center, and a central city of the Central Plains City Group. Guangzhou is located in southern China, bordering the South China Sea and the northern edge of the Pearl River Delta. It is the headquarters of the Southern China Theater Command, a comprehensive national gateway city, and the first coastal open city. It is China's southern gate to the world. The central city of the Pearl River Delta Economic Zone and the hub city of the Belt and Road Initiative. Nanjing is located in the east of China, the lower reaches of the Yangtze River, and the coastal waters. It is the headquarters of the East China Theater Command, a national logistics hub, and the Yangtze River International Shipping Logistics Center. An important node city that strategically intersects the Yangtze River Economic Belt. Considering the coverage area of the airline network, the geographical location of the city where the airport is located, the passenger throughput, the availability of data, and the actual situation of the cities in China are considered comprehensively. The case study selects Shenyang, Beijing, Qingdao, Zhengzhou, Guangzhou, and Nanjing as the research objects, which are numbered as 1, 2, 3, 4, 5, and 6, respectively. Also, this case study chooses two cities as a hub $(p=2)$, thereby constructing a hub-and-spoke network. Since the hub-and-spoke network is economies of scale, it is assumed that the discount coefficients for the collection, distribution, and transfer phases are $\chi=\delta=1, \alpha=0.5$ [44], respectively. We only consider the distance cost between cities as transportation cost. The transportation cost and demand cost among the six cities are obtained by consulting the "Statistical Civil Aviation 2015" [45]. The specific distance cost matrix can be obtained from Table 1; the demand cost matrix is the passenger flow of the corresponding segment, which is given in Table 2 .

4.2. Point-to-Point Network versus Hub-And-Spoke Network Emissions Calculation. Further, aircraft emissions are calculated by the aircraft emission assessment model. In order to conduct an in-depth study on the operating environment of the hub-and-spoke network and quantify the operational environmental impact of the network, we compare the aircraft emissions and fuel consumption between the huband-spoke network and the point-to-point network.

Taking into account the economies of scale of the huband-spoke network and combining the actual operation of each segment between cities and the operational characteristics of the hub-and-spoke network, we select three types 
TABLE 1: Distance cost matrix.

\begin{tabular}{lcccccc}
\hline Distance $(\mathrm{km})$ & Shenyang & Beijing & Qingdao & Zhengzhou & Guangzhou & Nanjing \\
\hline Shenyang & 0 & 730 & 821 & 1339 & 690 & 1630 \\
Beijing & 730 & 0 & 646 & 741 & 981 \\
Qingdao & 821 & 646 & 741 & 0 & 1967 & 567 \\
Zhengzhou & 1339 & 690 & 1867 & 1389 & 630 \\
Guangzhou & 2672 & 1967 & 552 & 630 & 0 & 1259 \\
Nanjing & 1630 & 981 & & & 0 \\
\hline
\end{tabular}

TABle 2: Demand matrix.

\begin{tabular}{|c|c|c|c|c|c|c|}
\hline Passenger flow (ten thousand) & Shenyang & Beijing & Qingdao & Zhengzhou & Guangzhou & Nanjing \\
\hline Shenyang & 0 & 113.5 & 42.8 & 0 & 60.3 & 35.1 \\
\hline Beijing & 113.5 & 0 & 131.2 & 0 & 411.7 & 85.1 \\
\hline Qingdao & 42.8 & 131.2 & 0 & 0 & 63.1 & 0 \\
\hline Zhengzhou & 0 & 0 & 0 & 0 & 79.4 & 0 \\
\hline Guangzhou & 60.3 & 411.7 & 63.2 & 79.4 & 0 & 149.2 \\
\hline Nanjing & 35.1 & 85.1 & 0 & 0 & 149.2 & 0 \\
\hline
\end{tabular}

of heavy aircraft, A330-200, B767, and A300 (20 airplanes of each) with a large number of seats between the hubs for transfer component, and the A319, A320 and B737 (100 airplanes of each) medium-size aircraft with a moderate number of seats between nonhub and hub for collection and distribution components [46]. In conjunction with the Engine Emissions Data Bank (EEDB) provided by ICAO, we can calculate the aircraft pollutant emissions. The aircraft pollutant emissions of the LTO cycle can be calculated directly by querying ICAO's EDB, but ICAO does not give the fuel consumption reference values and pollutant emission index during the cruise phase. According to the literature $[10,47]$, the engine thrust level during the cruise phase is generally $85 \%$, which is the same as the engine thrust level of the aircraft during the climb phase. Therefore, we use the relevant values in the working state of the climbing phase as the basis for calculating the pollutant emissions in the aircraft cruise phase. The number of seats and pollutant emission index of each type of aircraft are shown in Table 3. The fuel consumption reference values of each type of aircraft are shown in Table 4.

As shown in Table 3, for different types of aircraft, they have different passenger seat capacities. For example, for an A319 aircraft, it can accommodate 122 passengers. For a B767 aircraft, it can carry 225 passengers. For different types of aircraft, their engine models are also different. Different models of engines have different emission indices. For example, for the A319 type aircraft, its engine model is V2522$\mathrm{A} 5$, and it has different pollutant emission indexes during the climb and descent phases. $\mathrm{EI}_{\mathrm{CO}}, \mathrm{EI}_{\mathrm{HC}}$, and $\mathrm{EI}_{\mathrm{NOx}}$ are in units of grams of pollutants per kilogram of fuel $(\mathrm{g} / \mathrm{kg})$ for $\mathrm{CO}, \mathrm{HC}$, and NOx, respectively. During the climb phase, $\mathrm{EI}_{\mathrm{CO}}$ is the $\mathrm{CO}$ emission index (which is $0.44 \mathrm{~g} \mathrm{CO} / \mathrm{kg}$ fuel). In the declining phase, $\mathrm{EI}_{\mathrm{CO}}$ is the $\mathrm{CO}$ emission index (which is $2.55 \mathrm{~g} \mathrm{CO} / \mathrm{kg}$ fuel). Similarly, during the climb and descent phases, the $\mathrm{HC}$ emission index is represented by $\mathrm{EI}_{\mathrm{HC}}$ (which are $0.04 \mathrm{~g} \mathrm{HC} / \mathrm{kg}$ fuel and $0.07 \mathrm{~g} \mathrm{HC} / \mathrm{kg}$ fuel), respectively. In the declining phase, the $\mathrm{NO}_{\mathrm{x}}$ emission index represented by $\mathrm{EI}_{\mathrm{NOx}}$ (which is $18.32 \mathrm{~g} \mathrm{HC} / \mathrm{kg}$ fuel and $9.32 \mathrm{~g}$
$\mathrm{HC} / \mathrm{kg}$ fuel). As can be seen from Table $4, C f_{1}$ and $C f_{2}$ are the fuel consumption coefficients of the first unit thrust and the second unit thrust, respectively. $C f_{3}$ and $C f_{4}$ are the fuel flow coefficients of the first descent phase and the second descent phase, respectively, and $C f_{r}$ is the fuel flow coefficient of the cruise phase.

In a point-to-point network among six cities, each two cities are combined into one city pair. There are 15 city pairs, namely, Shenyang and Beijing, Shenyang and Qingdao, Shenyang and Zhengzhou, Shenyang and Guangzhou, Shenyang and Nanjing, Beijing and Qingdao, Beijing and Zhengzhou, Beijing and Guangzhou, Beijing and Nanjing, Qingdao and Zhengzhou, Qingdao and Guangzhou, Qingdao and Nanjing, Zhengzhou and Guangzhou, Zhengzhou and Nanjing, Guangzhou and Nanjing. Since Shenyang and Zhengzhou, Beijing and Zhengzhou, Qingdao and Zhengzhou, Qingdao and Nanjing, and Zhengzhou and Nanjing. The traffic volume is 0 , that is, regardless of the no traffic flow between two cities, it becomes 10 city pairs. Through the Flight Aware official website, query and analyze the actual flight trajectory data of the three types of aircraft using A319, A320, and B737 during normal departure and arrival.

4.3. Analysis of Results. According to equations (1)-(8), using MATLAB2016a to run on Intel $(R)$ Core (TM) i7-7700 CPU $3.60 \mathrm{GHz} / 8.00 \mathrm{~GB}$ computer, we can get the hub-andspoke network as shown in Figure 2.

In Figure 2, city 2 and city 5 are hub nodes, cities 1, 3, 4, and 6 are nonhub nodes, which denote Beijing and Guangzhou as hub nodes, Shenyang, Qingdao, Zhengzhou and Nanjing as nonhub nodes, and specific airline network arrangements as shown in Table 5 .

From Table 5, we observe that $h_{2}=h_{5}=1$, indicating that node 2 and node 5 are hub nodes; that is, Beijing and Guangzhou as hubs, and the optimal total transportation cost is $\$ 3.63 E+5 . x_{1222=1}$ denotes that Shenyang and Beijing are connected, and $x_{1322}$ indicates that the passenger flow 
TABLE 3: Relevant data of each type of aircraft.

\begin{tabular}{lcccccccc}
\hline \multirow{2}{*}{ Aircraft type } & \multirow{2}{*}{ Engine model } & \multirow{2}{*}{ Capacity (in passengers) } & \multicolumn{2}{c}{$\mathrm{EI}_{\mathrm{CO}}(\mathrm{g} / \mathrm{kg})$} & \multicolumn{2}{c}{$\mathrm{EI}_{\mathrm{HC}}(\mathrm{g} / \mathrm{kg})$} & \multicolumn{2}{c}{$\mathrm{EI}_{\mathrm{NOX}}(\mathrm{g} / \mathrm{kg})$} \\
& & & Climb & Descent & Climb & Descent & Climb & Descent \\
\hline A319 & V2522-A5 & 122 & 0.44 & 2.55 & 0.04 & 0.07 & 18.32 & 9.32 \\
A320 & CFM56-5A1 & 150 & 0.90 & 2.5 & 0.23 & 0.4 & 19.6 & 8 \\
B737 & CFM56-7B26 & 147 & 0.60 & 1.6 & 0.1 & 0.1 & 22.5 & 10.8 \\
A330-200 & CF6-80E1A2 & 253 & 0.34 & 1.61 & 0.07 & 0.14 & 28.02 & 9.91 \\
B767 & CF6-80C2B (F) & 225 & 0.52 & 2.93 & 0.09 & 0.23 & 18.32 & 8.54 \\
A300 & PW4158 & 280 & 0.54 & 1.88 & 0.02 & 0.14 & 23.7 & 11.8 \\
\hline
\end{tabular}

TABLE 4: Fuel consumption reference value for each type of aircraft.

\begin{tabular}{lcccccc}
\hline Aircraft type & Number & $C f_{1}(\mathrm{~kg} /(\mathrm{min} \cdot \mathrm{kN}))$ & $C f_{2}(\mathrm{knots})$ & $C f_{3}(\mathrm{~kg} / \mathrm{min})$ & $C f_{4}(\mathrm{feet})$ & $C f_{r}(\mathrm{dimensionless})$ \\
\hline A319 & 1 & 0.72891 & 1729.80 & 11.114 & 133850 & 0.99224 \\
A320 & 2 & 0.75882 & 2938.50 & 8.942 & 93865 & 0.96358 \\
B737 & 3 & 0.68640 & 952.85 & 10.592 & 59399 & 0.93420 \\
A330-200 & 4 & 0.61503 & 919.03 & 21.033 & 112230 & 0.93655 \\
B767 & 5 & 0.62911 & 851.87 & 20.794 & 66506 & 0.91891 \\
A300 & 6 & 0.63936 & 1004.70 & 21.196 & 67071 & 0.98852 \\
\hline
\end{tabular}

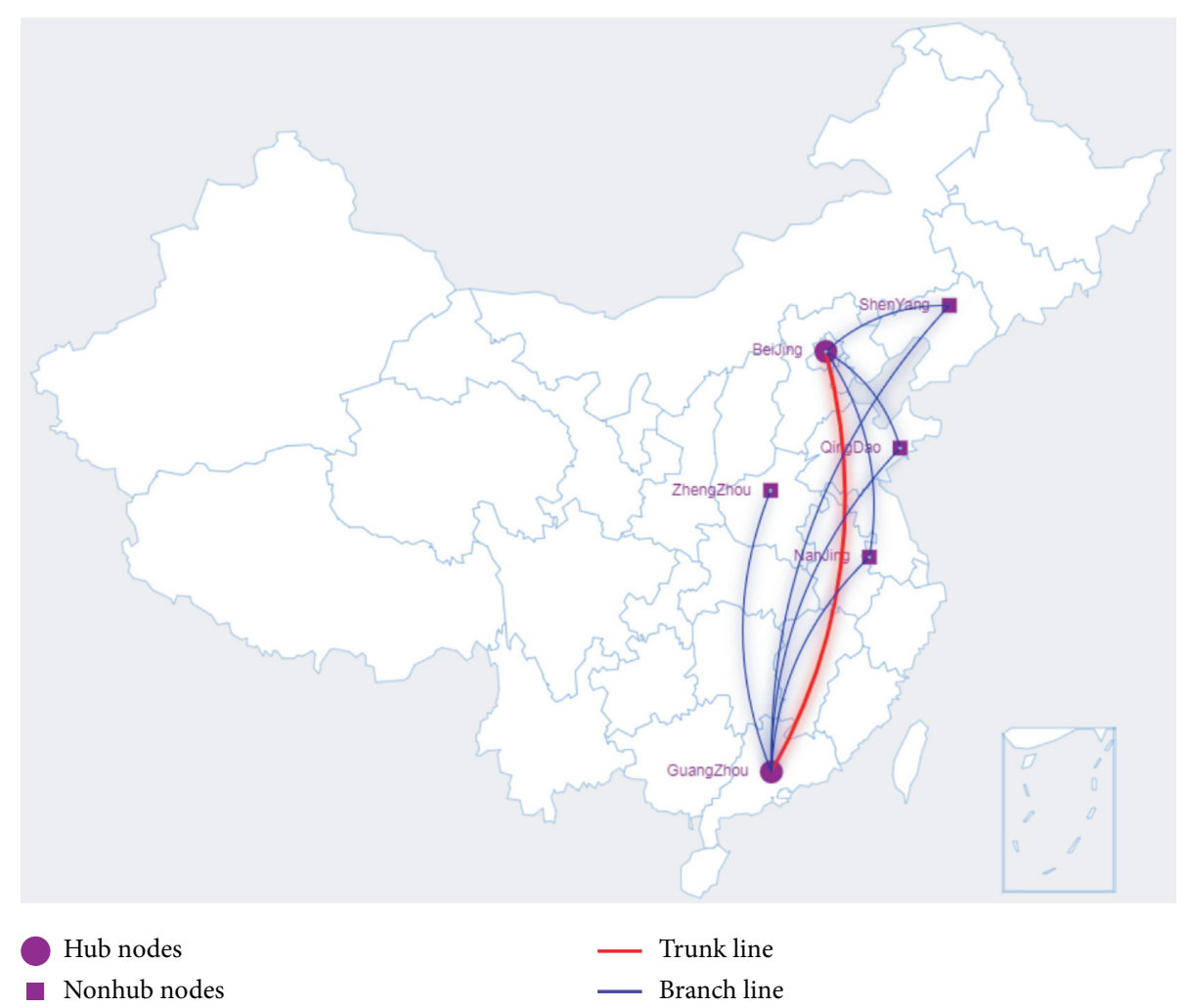

FIgURE 2: Hub-and-spoke network composed of six cities.

Table 5: Arrangements of hub-and-spoke network.

\begin{tabular}{lcl}
\hline$h_{2}=1$ & $h_{5}=1$ & $x_{1222}=1$ \\
\hline$x_{1322}=1$ & $x_{1455}=1$ & $x_{1525}=1$ \\
$x_{1622}=1$ & $x_{2322}=1$ & $x_{2455}=1$ \\
$x_{2525}=1$ & $x_{2622}=1$ & $x_{3455}=1$ \\
$x_{3525}=1$ & $x_{3622}=1$ & $x_{3655}=1$ \\
$x_{4555}=1$ & $x_{4655}=1$ & $x_{5655}=1$ \\
\hline
\end{tabular}

between the nonhubs Shenyang and Qingdao passes through the hub of Beijing for transfer. Similarly, nonhubs Qingdao, Nanjing, and hub Beijing are connected, and nonhubs Zhengzhou, Qingdao, Nanjing, and hub Guangzhou are connected. Passenger flow between nonhub Shenyang and Nanjing, Qingdao and Nanjing through the hub of Beijing for transfer. Passengers among nonhub Shenyang and Zhengzhou, Qingdao and Zhengzhou, Qingdao and Nanj- 
ing, Zhengzhou and Nanjing transfer through Guangzhou. In summary, based on the determined location of the hub nodes and the airline arrangement between the hub node and the nonhub node, the hub-and-spoke network structure is obtained.

In order to improve the credibility of the research results and guarantee the consistency of the variables, we need to ensure the flow conservation of the two types of the network when comparing the hub-and-spoke network with the point-to-point network. Therefore, the types and quantities of aircraft used in different airline network will be different. By consulting the Aircraft Noise Performance (ANP) database website and combining the number of seats in each type of aircraft in Table 3, we need to reasonably assign the type of aircraft for each flight segment.

As is shown in Figure 2, if the hub-and-spoke network is used between the six cities, combined with the actual situation, the hub between Beijing and Guangzhou is transfer component, Shenyang and Beijing, Beijing and Qingdao, Beijing and Nanjing, Guangzhou and Zhengzhou, Qingdao and Guangzhou, Guangzhou and Nanjing, Shenyang and Guangzhou, are the component of collection and distribution component. According to Figure 3, only 20 flights of A330-200 between hubs were chosen as examples for data analysis due to the complex data processing. In the collection and distribution component, the operation situation of the 20 flights with A320 is only taken as an example are depicted in Figure 4.

Figure 3 depicts the flight operation situation between hub nodes. The median position of flight operations between Beijing and Guangzhou is mostly at the altitude of 9,000 to 12,000 meters; except for individual flights, the position and height of the interquartile range are basically the same. From the upper and lower limits of Whisker, the flight altitude of a few flights is slightly larger, indicating that the operational situation between Beijing and Guangzhou is relatively stable, and the availability of experimental data is better.

Figure 4 shows the flight operation situation between the hub node and nonhub node. It is known from Figure 4(b) that the median position of the flight altitude between Beijing and Qingdao is basically at the altitude of 3000 to 5000 meters, and the position and height of the interquartile range frame are basically the same. From the upper and lower limits of Whisker, the flight altitude of the flight operation data is roughly the same, indicating that the operational situation between Beijing and Qingdao is relatively stable, and the availability of experimental calculations is better. It is depicted in Figure 4(c), Figure 4(e) and Figure 4(f), the median flying altitude of the four city pairs in Beijing and Nanjing, Qingdao and Guangzhou, Guangzhou and Nanjing is 6000 to 7000 meters, 9000 to 10000 meters and 5000 to 7000 meters, respectively. The position and height of the interquartile range of each city pair are basically the same. From the upper and lower limits of Whisker, the flight altitude range of each city is roughly the same, indicating that the operation situation of the seven city pairs is relatively stable. From Figure 4(a) and Figure 4(g), it can be seen that the median position of flight altitude of Shenyang and Beijing, Shenyang and Guangzhou is at the altitude of

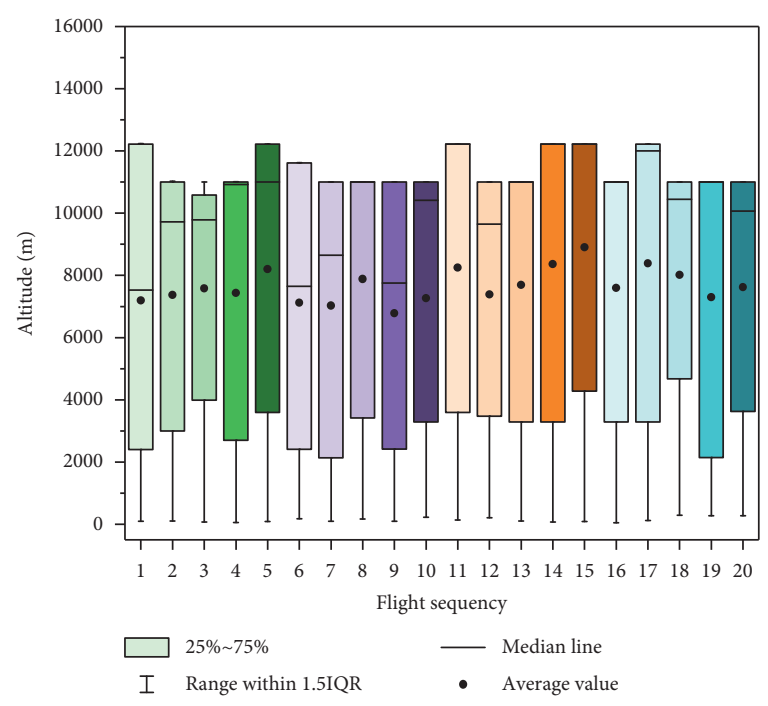

Figure 3: The flight operation situation of A330-200 between Beijing and Guangzhou.

2000 to 3500 meters and 8000 to 10000 meters, respectively. The position and height of the interquartile range between Shenyang and Beijing are quite different. Except for individual flights, the position and height of the interquartile range between Shenyang and Guangzhou are approximately the same. From the upper and lower limits of Whisker, the flight altitude of Shenyang and Beijing is larger, may be subject to weather conditions, regulatory reasons, airspace activities, etc. The flight altitude ranges of most flights between Shenyang and Guangzhou are roughly the same, and the data status is relatively stable.

In Figure 3, the flight operation situation between Beijing and Guangzhou is stable and the data is in good condition. By taking a mathematical analysis, flight data that can be used for calculation is obtained, and a three-dimensional mesh graph is drawn to represent the flight profile of the flight. Because of the heavy-duty transportation between the hubs, the A330-200 is used as an example to analyze the data, and the flight profile presented in Figure 5 is obtained. The green dots indicate the flight trajectory of the flight.

From the above analysis, it can be seen that in the operation of the hub-and-spoke network, the flight operation data between the cities used in this paper is generally stable, indicating that our experimental data has good robustness and can be served for the calculations. In individual city pairs, we preprocess the flight data for the segments with poor robustness to facilitate the calculation.

Here, only the four city pairs of Beijing and Qingdao, Beijing and Nanjing, Qingdao and Guangzhou, and Guangzhou and Nanjing are used to draw three-dimensional mesh graphs to represent the flight profiles between the hub node and the nonhub node.

The graphic drawing of other city pairs is similar and will not be listed in detail here. A three-dimensional mesh graph as depicted in Figure 6 is obtained for our calculations. Figure 6(a) to Figure 6(d) are flight profiles of Beijing and 


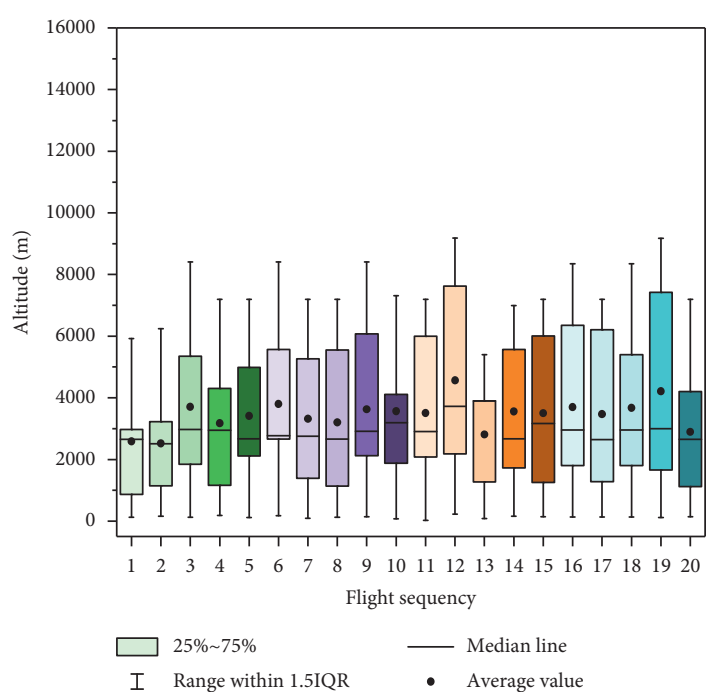

(a)

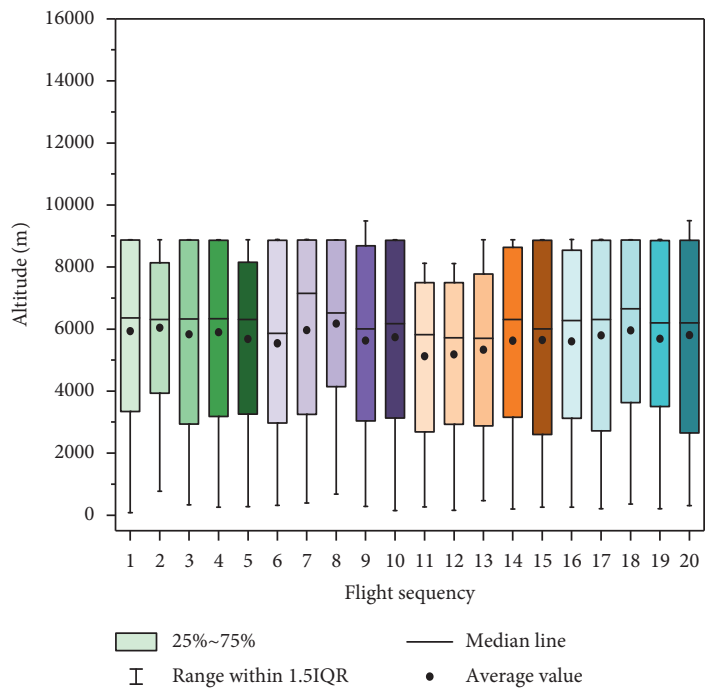

(c)

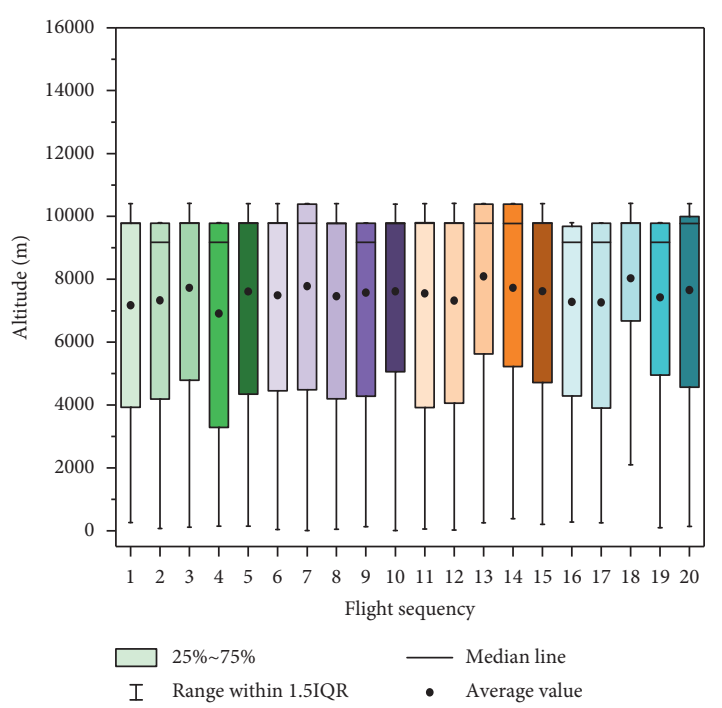

(e)

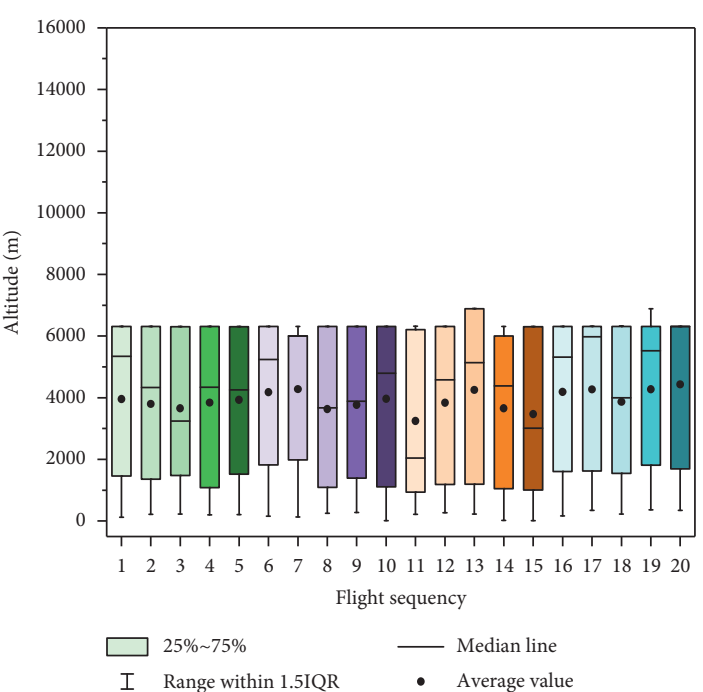

(b)

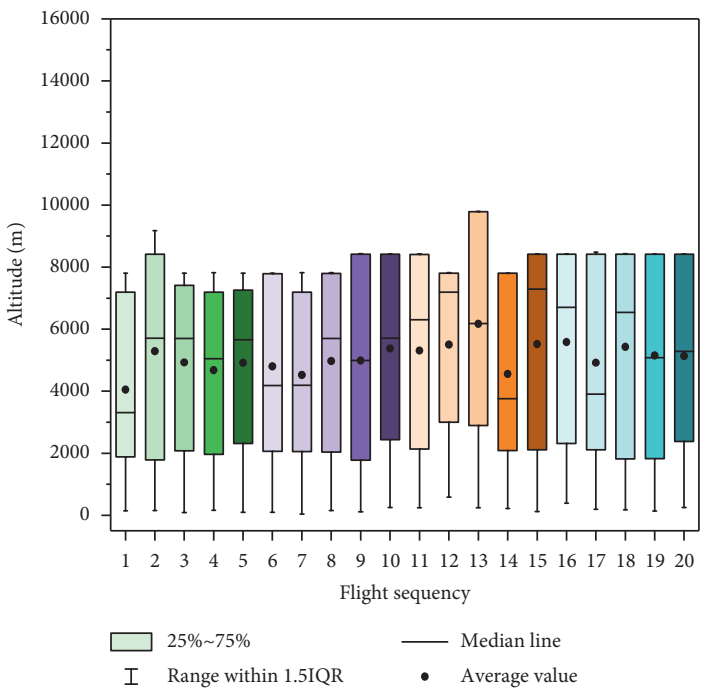

(d)

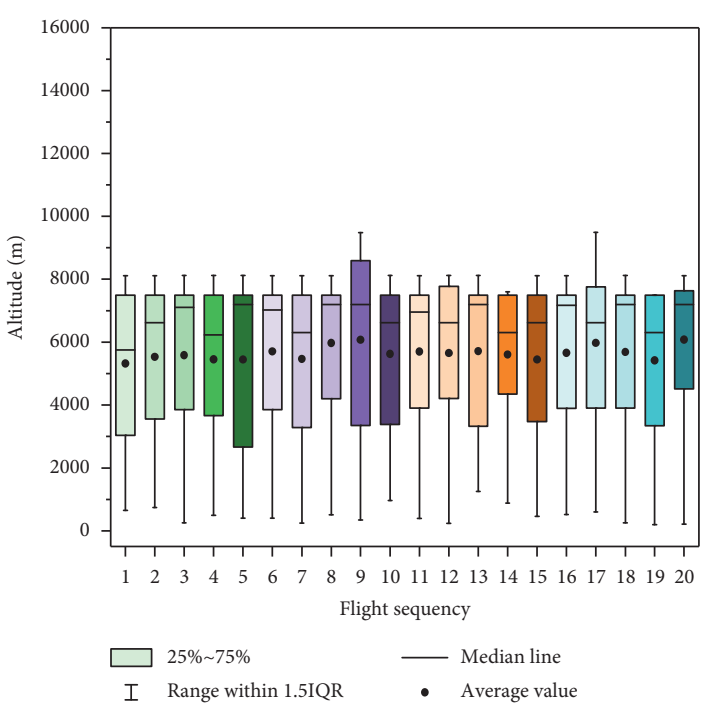

(f)

Figure 4: Continued. 


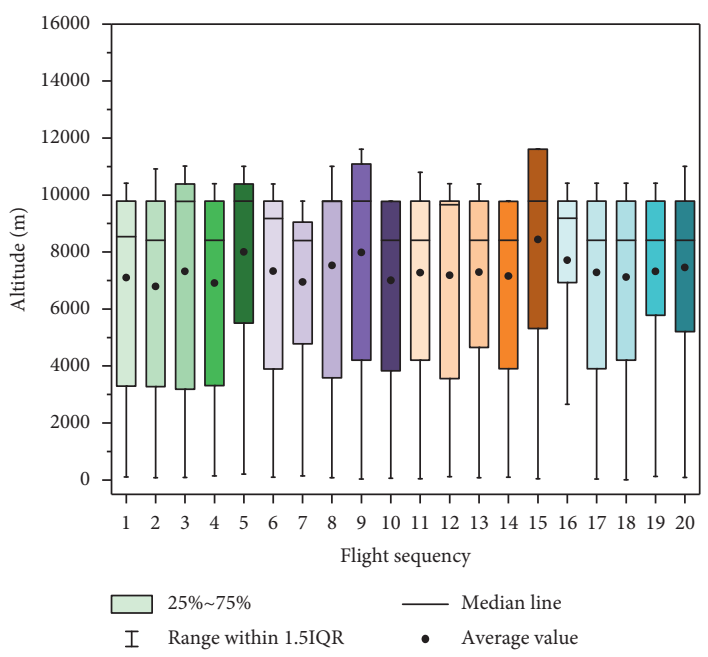

(g)

FIgURE 4: The flight operation situation of A320 in the hub-and-spoke network. (a) Between Shenyang and Beijing. (b) Between Beijing and Qingdao. (c) Between Beijing and Nanjing. (d) Between Guangzhou and Zhengzhou. (e) Between Qingdao and Guangzhou. (f) Between Guangzhou and Nanjing. (g) Between Shenyang and Guangzhou.

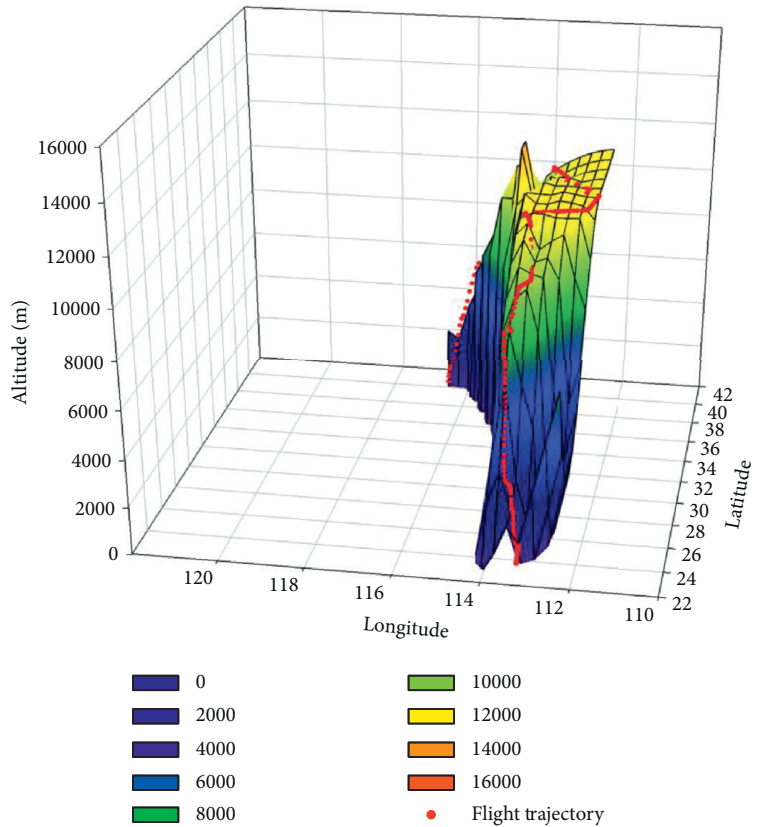

FIgUre 5: The flight profile for calculating A330-200 between Beijing and Guangzhou.

Qingdao, Beijing and Nanjing, Qingdao and Guangzhou, and Guangzhou and Nanjing, respectively, and red dots indicate the flight trajectory of the flight. The results shown in Table 6 were obtained by calculating the pollutant emissions and fuel consumption during the climb, descent, and cruise phases of the aircraft operating in the hub-andspoke network.

Similarly, if a point-to-point network is used among six cities, that is, a direct flight between each two cities, there are 10 city pairs. In order to ensure the conservation of passenger flows during the operation of the two airline networks, we combine the number of seats of each aircraft type in Table 2 to obtain 133, 133, and 134 aircraft of A319, A320, and B737. Since the flight operation situation of the hub-and-spoke network has been shown in the foregoing, which also includes the flight segments corresponding to the point-to-point network, the analysis is not enumerated here. The flight profiles of the flights are also depicted by drawing three-dimensional mesh graphs for our calculations, and no further analysis is performed here. We get the aircraft operating impact in the point-to-point network, the pollutant emissions, and fuel consumption during the climb, descent, and cruise phases are shown in Table 7.

We also analyze the flight profiles of the aircraft by drawing three-dimensional mesh graphs. We will not draw pictures here. We use the obtained better profile to calculate the pollutant emissions and fuel consumption during the climb, descent, and cruise phases. The results are provided in Table 7.

Based on Tables 6 and 7, the total emissions (including various types of pollutants during the climb, descent, and cruise phases) and total fuel consumption during the operation of the hub-and-spoke network and the point-topoint network among the six cities are summarized in Table 8.

As suggested by Table 8 , the total $\mathrm{CO}$ emissions represent the total $\mathrm{CO}$ emissions of the aircraft during the climb, descent, and cruise phases. The total HC emissions show the total $\mathrm{HC}$ emissions during the climb, descent, and cruise phases. The total $\mathrm{NO}_{\mathrm{x}}$ emissions express the total $\mathrm{NO}_{\mathrm{x}}$ emissions during the climb, descent, and cruise phases. Pollutant emissions denote the total emissions of pollutants (including $\mathrm{CO}, \mathrm{HC}$, and $\mathrm{NO}_{\mathrm{x}}$ ) during the climb, descent, and cruise phases. According to the comparative analysis of pollutant emissions and fuel consumption of the hub-andspoke network and the point-to-point network in Table 6, it can be seen that the operation of the flight by the hub-and- 


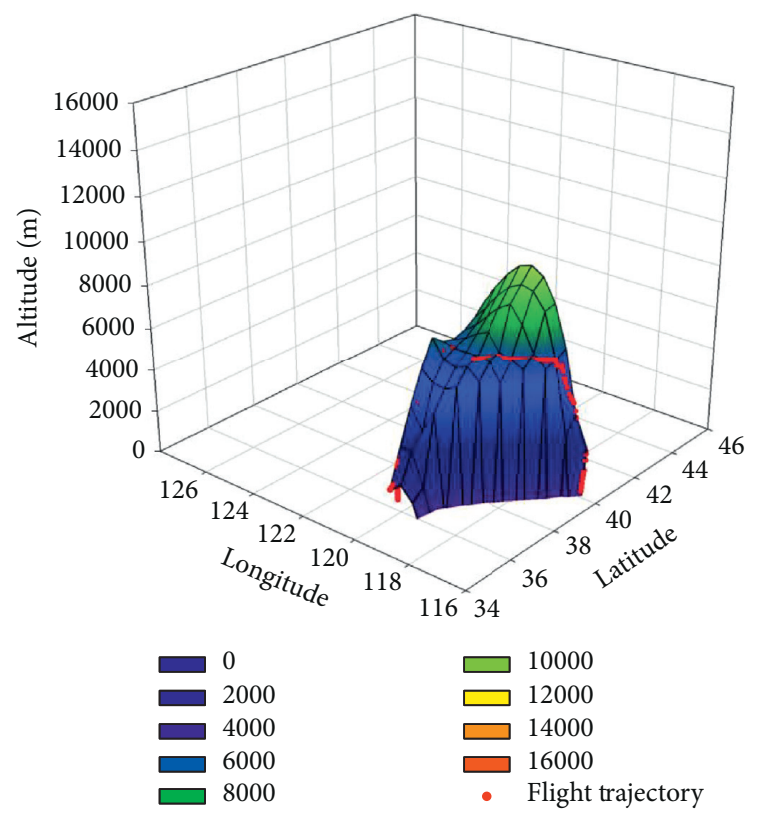

(a)

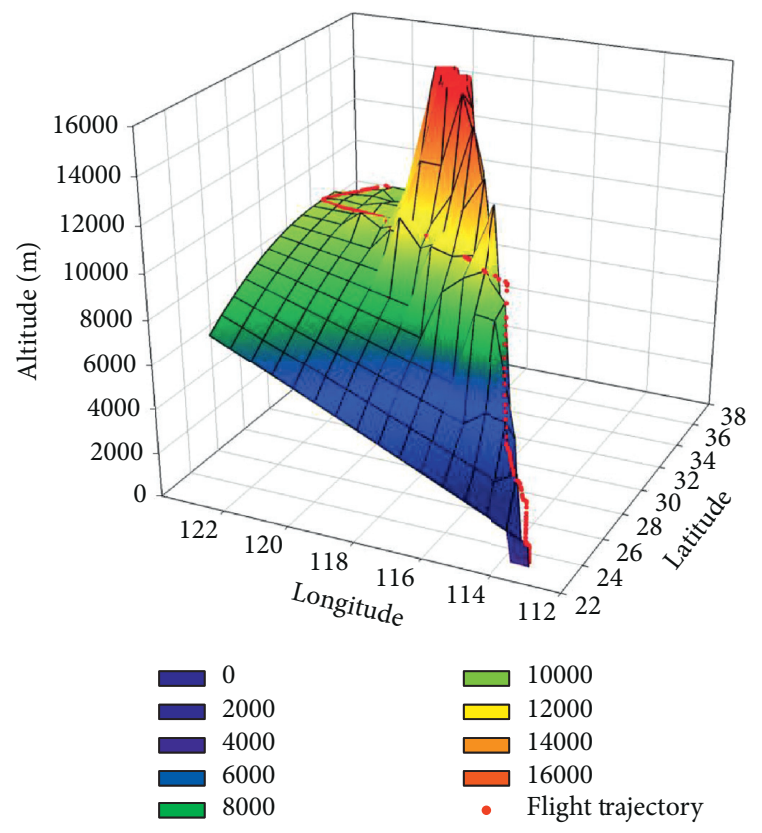

(c)

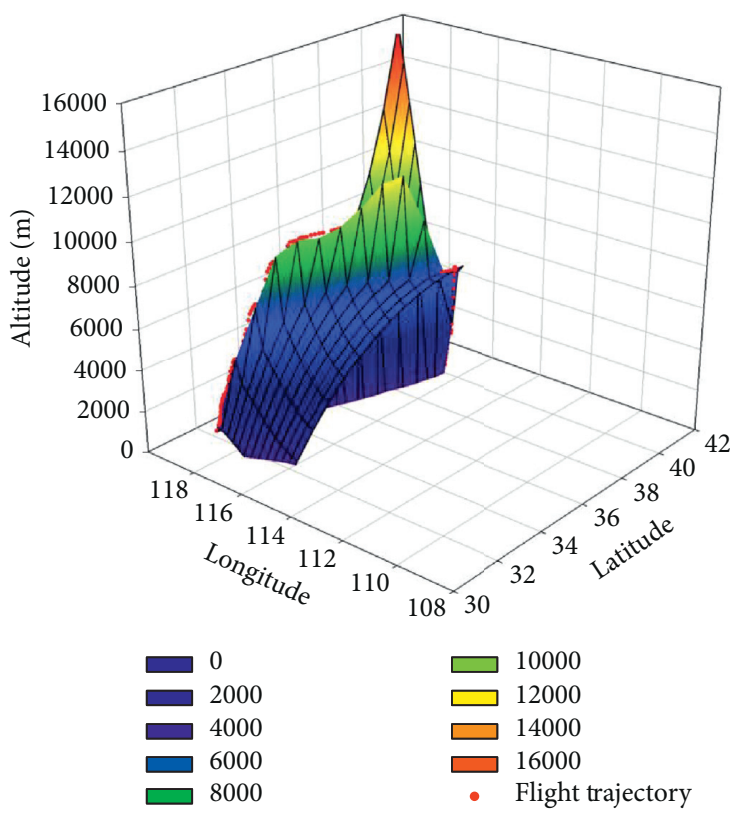

(b)

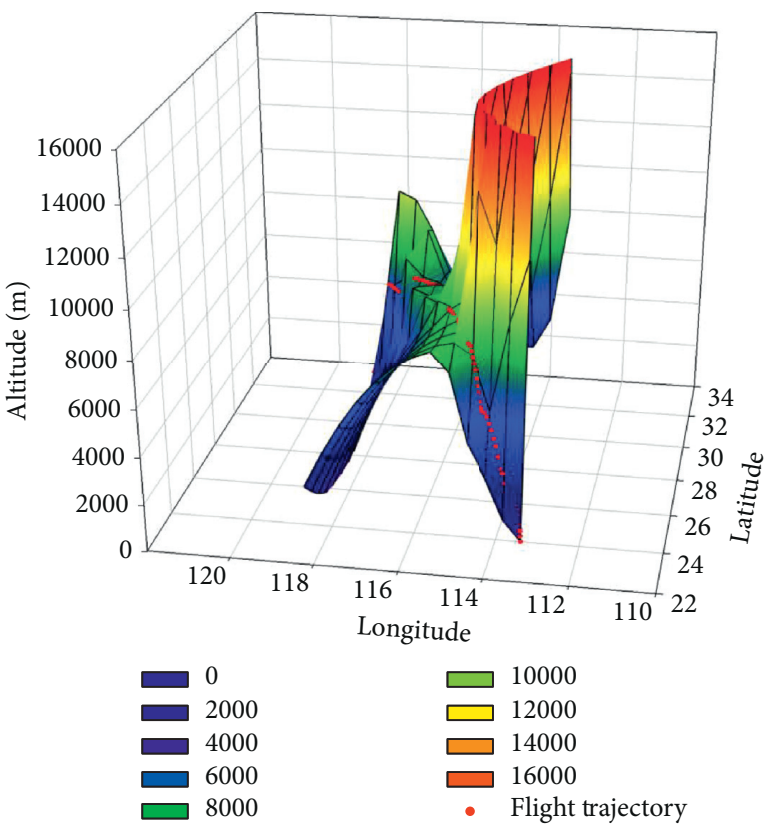

(d)

FIGURE 6: The flight profile for calculating the aircraft A320 in the hub-and-spoke network flight operation situation of A320 in the hub-andspoke network. (a) Between Beijing and Qingdao. (b) Between Beijing and Nanjing. (c) Between Qingdao and Guangzhou. (d) Between Guangzhou and Nanjing.

TABLE 6: Hub-and-spoke network pollutant emissions and fuel consumption.

\begin{tabular}{lcc}
\hline Pollutant emissions and fuel consumption & Climbing and descending stages $(\mathrm{kg})$ & Cruise phase $(\mathrm{kg})$ \\
\hline CO emission & $1.42 E+8$ & $3.57 E+8$ \\
HC emission & $1.14 E+7$ & $2.46 E+7$ \\
NOx emission & $4.47 E+8$ & $1.16 E+9$ \\
Fuel consumption & $1.37 E+6$ & $1.20 E+8$ \\
\hline
\end{tabular}

spoke network reduced the total CO emissions by $35.84 \%$ and the total $\mathrm{HC}$ emissions by $68.82 \%$, and total $\mathrm{NO}_{\mathrm{x}}$ emissions increased by $24.87 \%$. Total pollutant emissions decreased by $29.37 \%$, and total fuel consumption reduced by $68.17 \%$. In general, the use of a hub-and-spoke network between cities can save a certain transportation cost and can 
TABLe 7: Point-to-point network pollutant emissions and fuel consumption.

\begin{tabular}{lcc}
\hline Pollutant emissions and fuel consumption & Climbing and descending stages $(\mathrm{kg})$ & Cruise $\mathrm{phase}(\mathrm{kg})$ \\
\hline $\mathrm{CO}$ emission & $1.13 E+8$ & $6.64 E+8$ \\
$\mathrm{HC}$ emission & $9.47 E+6$ & $1.06 E+8$ \\
$\mathrm{NO}_{\mathrm{x}}$ emission & $3.15 E+8$ & $1.05 E+9$ \\
Fuel consumption & $3.44 E+6$ & $2.00 E+8$ \\
\hline
\end{tabular}

TABLE 8: Contrast of pollutant emissions and fuel consumption.

\begin{tabular}{lcc}
\hline Pollutant emissions and fuel consumption & Hub-and-spoke network $(\mathrm{kg})$ & Point-to-point network (kg) \\
\hline Total CO emission & $4.99 E+8$ & $7.77 E+8$ \\
Total HC emission & $3.60 E+7$ & $1.15 E+8$ \\
Total $\mathrm{NO}_{\mathrm{x}}$ emission & $1.60 E+9$ & $2.14 E+9$ \\
Pollutant emissions & $2.14 E+9$ & $3.03 E+9$ \\
Total fuel consumption & $1.21 E+7$ & $2.03 E+8$ \\
\hline
\end{tabular}

reduce pollutant emissions and fuel consumption due to air transportation as a whole.

The reason is mainly due to the use of the hub-and-spoke network to collect the nonhub passenger through the largesize aircraft with a large number of seats to the hub airport, after transfer through the hub airport, the medium-size aircraft with moderate seats will be used to distribute passengers to destinations, reflecting economies of scale while reducing the environmental impact of aircraft emissions. When the point-to-point network is operated, only the traffic flow between the two airports is considered, and the connection problem between the airlines of the same city cannot be considered, so that the effective configuration of the regional resources cannot be formed. Moreover, the carrier rate and the passenger load factor between nonhub airports are low, causing airlines to experience operational losses. In addition, passenger destination requirements have additionally increased the number of takeoffs and landings of flights, resulting in increased fuel consumption and aircraft emissions.

\section{Conclusions}

This paper determines the location of the hub airport through the hub location model, uses the aircraft emission assessment model to calculate the mass of pollutant emissions (mainly including $\mathrm{CO}, \mathrm{HC}$, and $\mathrm{NO}_{\mathrm{x}}$ ) and fuel consumption of aircraft, and analyze the operational environmental impact of the hub-and-spoke network with the case study. Based on the basic conditions met in this study, a comparative analysis of the hub-and-spoke network and the point-to-point network was performed, and some results were obtained.

This study comprehensively considers the availability of data such as the geographical location of the city, the passenger flow of the flight segment, and the flight segment distance. Six representative cities are selected as research objects for example analysis. According to the established mathematical model, taking the lowest total transportation cost as the objective function, the location of the hub airport, and the airline assignment and connection method are obtained. For the flight data obtained, the aircraft's operating situation diagram is drawn to analyze the stability and robustness of the data. The data with better robustness can be used directly, and the data with slightly less stability is preprocessed and then used. By drawing a 3D mesh flight profile graph between hub node and nonhub node, the aircraft's flight trajectory can be found, thereby laying the foundation for the pollutant emissions and fuel consumption of the airline network. Based on the operating characteristics of the hub-and-spoke network and the point-topoint network, the flight segments between each city pair are analyzed and calculated, and the pollutant emissions and fuel consumption of the aircraft in the airline network are finally obtained.

Through the comparative analysis of pollutant emissions and fuel consumption between the hub-and-spoke network and the point-to-point network, the results showed that the operation of the flight using the hub-and-spoke network reduced the total $\mathrm{CO}$ emissions by $35.84 \%$, the total $\mathrm{HC}$ emissions by $68.82 \%$, and total $\mathrm{NO}_{\mathrm{x}}$ emissions increased by $24.87 \%$. The total mass of pollutant emissions decreased by $29.37 \%$, total fuel consumption reduced by $68.17 \%$, and total transportation cost was as low as $\$ 3.63 \mathrm{E}+5$. In the operation process of the hub-and-spoke network, it reflected its economies of scale, reduced the fuel consumption, and decreased the mass of pollutant emissions of aircraft, which complied with the development theme of green civil aviation in the "13th Five-Year Plan" of civil aviation, China.

This study is suitable for evaluation calculations under certain restrictions. The analysis is based on the flight data of each segment of the Flight Aware official website. As a further study it can be proposed to consider the economic cost, environmental factors, and time factors comprehensively, establish a multiobjective optimization model and use an efficient solution algorithm for further research.

A large number of studies have shown that the rapid development of the civil aviation transportation industry has gradually made the emission of pollutants from aircraft an important aspect of urban air pollution. Aircraft fly in the airline network and emit a large number of pollutants into the air during the flight. The distribution and connection methods will lead to a different situation of aviation emissions. To address this point, this study compares the hub- 
and-spoke network with the point-to-point network and studies the environmental impact of the two network states. It was found that, with the lowest total transportation costs, the emissions and fuel consumption of the hub-and-spoke network have less impact than the point-to-point network. At the same time, the international authorities' awareness of environmental protection is increasing. With the continuous increase in fuel prices and tourism industry demand, airlines are also required to adopt corresponding competition strategies in fuel management to control excessive fuel consumption and achieve long-term sustainable development. Therefore, the situation of fuel consumption is also worthy of attention. The comparative analysis of the two airline networks shows that the fuel consumption of the huband-spoke network is also lower than that of the point-topoint network. To sum up, this study starts from an environmental perspective and conducts an environmental impact analysis for different airline networks. It summarizes the airline network form with smaller pollutant emissions and lower fuel consumption. A certain reference role provides a more effective way for airlines to improve fuel efficiency and provides a new environmental protection direction for airlines to reduce pollution. The research of this topic helps airlines better realize environmental protection, which not only saves fuel but also accelerates the use of similar research in the aviation field.

\section{Data Availability}

The actual flight trajectory data were downloaded from Flight Aware official website, and the data used to calculate emissions can be downloaded from Aircraft Noise Performance (ANP) database website. The other data used to support the findings of this study are available from the corresponding author upon request.

\section{Conflicts of Interest}

The authors declare that there are no conflicts of interest regarding the publication of this paper.

\section{Acknowledgments}

The research was supported by the National Natural Science Foundation of China (grant no. 61671237) and Foundation of Graduate Innovation Center in Nanjing University of Aeronautics and Astronautics (grant no. kfjj20190711).

\section{References}

[1] A. W. SchäFer, A. D. Evans, T. G. Reynolds, and L. Dray, "Costs of mitigating CO2 emissions from passenger aircraft," Nature Climate Change, vol. 6, no. 4, pp. 412-417, 2016.

[2] S. Krile, M. Krile, and P. Průša, "Non-linear mini-max problem of multi-stop flight routes," Transport, vol. 30, no. 3, pp. 361-371, 2015.

[3] A. Dickinson, "The proposal for a regulation of the European parliament and of the Council on jurisdiction and the recognition and enforcement of judgments in civil and commercial matters (recast) "Brussels I bis"The proposal for a regulation of the European parliament and of the Council on jurisdiction and the recognition and enforcement of judgments in civil and commercial matters (recast) ('Brussels I bis' regulatio" regulation)," Social Science Electronic Publishing, vol. 11, no. 44, pp. 40-56, 2011.

[4] IATA, Fuel Fact Sheet, IATA, Montreal, Canada, 2019.

[5] P. Iodice and A. Senatore, "Air pollution and air quality state in an Italian national interest priority site. part 1: the emission inventory," Energy Procedia, vol. 81, pp. 628-636, 2015.

[6] P. Iodice and A. Senatore, "Air pollution and air quality state in an Italian national interest priority site. part 2: the pollutant dispersion," Energy Procedia, vol. 81, pp. 637-643, 2015.

[7] P. Iodice and A. Senatore, "Industrial and urban sources in Campania, Italy: the air pollution emission inventory," Energy \& Environment, vol. 26, no. 8, pp. 1305-1317, 2015.

[8] P. Iodice, P. Adamo, F. Capozzi et al., "Air pollution monitoring using emission inventories combined with the moss bag approach," Science of The Total Environment, vol. 541, pp. 1410-1419, 2016.

[9] D. Carslaw, S. Beevers, K. Ropkins, and M. Bell, "Detecting and quantifying aircraft and other on-airport contributions to ambient nitrogen oxides in the vicinity of a large international airport," Atmospheric Environment, vol. 40, no. 28, pp. 5424-5434, 2006.

[10] S. R. H. Barrett, R. E. Britter, and I. A. Waitz, "Global mortality attributable to aircraft cruise emissions," Environmental Science \& Technology, vol. 44, no. 19, pp. 7736-7742, 2010.

[11] C. S. Dorbian, P. J. Wolfe, and I. A. Waitz, "Estimating the climate and air quality benefits of aviation fuel and emissions reductions," Atmospheric Environment, vol. 45, no. 16, pp. 2750-2759, 2011.

[12] D. Chen and J. Sun, "Fuel and emission reduction assessment for civil aircraft engine fleet on-wing washing," Transportation Research Part D: Transport and Environment, vol. 65, pp. 324-331, 2018.

[13] A. K. Waqar, C. Sai-Ho, M. Hoi-Lam et al., "A novel selforganizing constructive neural network for estimating aircraft trip fuel consumption," Transportation Research Part E, vol. 132, pp. 72-96, 2019.

[14] Q. Zhu, J. Pei, X. Liu, and Z. Zhou, “Analyzing commercial aircraft fuel consumption during descent: a case study using an improved K-means clustering algorithm," Journal of Cleaner Production, vol. 223, no. 20, pp. 869-882, 2019.

[15] WIT Press, "The sustainable city II. urban regeneration and sustainability," in Proceedings of the TRB, p. 1034, Southampton, UK, October 2002.

[16] N. Giovanni, "A note on the competitive advantage of large hub-and-spoke networks"' Transportation Research Part E: Logistics and Transportation Review, vol. 35, pp. 225-239, 1999.

[17] J. Ebery, M. Krishnamoorthy, A. Ernst, and N. Boland, "The capacitated multiple allocation hub location problem: formulations and algorithms," European Journal of Operational Research, vol. 120, no. 3, pp. 614-631, 2000.

[18] J. F. Campbell and M. E. O'Kelly, “Twenty-five years of hub location research," Transport. Science, vol. 46, no. 2, pp. 153-169, 2012.

[19] G. Laporte, F. S. D. Gama, and S. Nickel, P-Center Problems, In Location Science, Springer, Berlin, Germany, 2015.

[20] Y. Gao and Z. Qin, "A chance constrained programming approach for uncertain p-hub center location problem," Computers \& Industrial Engineering, vol. 102, pp. 10-20, 2016. 
[21] İ. Akgün and B. C.. Tansel, "p-Hub median problem for noncomplete networks," Computers \& Operations Research, vol. 95, pp. 56-72, 2018.

[22] N. Ghaffarinasab, A. Motallebzadeh, Y. Jabarzadeh, and B. Y. Kara, "Efficient simulated annealing based solution approaches to the competitive single and multiple allocation hub location problems," Computers \& Operations Research, vol. 90, pp. 173-192, 2018.

[23] M. R. Amin-Naseri, A. Yazdekhasti, and A. Salmasnia, "Robust bi-objective optimization of uncapacitated single allocation p-hub median problem using a hybrid heuristic algorithm," Neural Computing and Applications, vol. 29, no. 9, pp. 511-532, 2018.

[24] L. Števárová and B. Badánik, "Performance of hub and spoke networks of selected airlines," Transportation Research Procedia, vol. 35, pp. 240-249, 2018.

[25] B. Soylu and H. Katip, "A multiobjective hub-airport location problem for an airline network design," European Journal of Operational Research, vol. 277, no. 2, pp. 412-425, 2019.

[26] ICAO, Environment, ICAO, Montreal, Canada, 2019, http:// www.icao.int/environmental-protection/Pages/market-basedmeasures_old.aspx.

[27] M. Peter and C. Lu, "The environmental cost implication of hub-hub versus hub by-pass flight networks," Transportation Research Part D Transport \& Environment, vol. 12, no. 3, pp. 143-157, 2007.

[28] B. Y. Kim, G. G. Fleming, J. J. Lee et al., "System for assessing Aviation's Global Emissions (SAGE), Part 1: model description and inventory results," Transportation Research Part D Transport and Environment, vol. 12, no. 5, pp. 25-346, 2007.

[29] D. S. Zachary, J. Gervais, and U. Leopold, "Multi-impact optimization to reduce aviation noise and emissions," Transportation Research Part D: Transport and Environment, vol. 15, no. 2, pp. 82-93, 2010.

[30] X. Prats, V. Puig, and J. Quevedo, "A multi-objective optimization strategy for designing aircraft noise abatement procedures. Case study at Girona airport," Transportation Research Part D: Transport and Environment, vol. 16, no. 1, pp. 31-41, 2011.

[31] S. A. Alumur, H. Yaman, and B. Y. Kara, "Hierarchical multimodal hub location problem with time-definite deliveries," Transportation Research Part E: Logistics and Transportation Review, vol. 48, no. 6, pp. 1107-1120, 2012.

[32] O. 'K. E. Morton, "Fuel burn and environmental implications of airline hub networks"' Transportation Research Part D, vol. 17, pp. 555-567, 2012.

[33] U. Kesgin, "Aircraft emissions at Turkish airports," Energy, vol. 31, no. 2-3, pp. 372-384, 2006.

[34] H. L. Khoo and L. E. Teoh, "A bi-objective dynamic programming approach for airline green fleet planning," Transportation Research Part D: Transport and Environment, vol. 33, pp. 166-185, 2014.

[35] B. Kim, L. Li, and J.-P. Clarke, "Runway assignments that minimize terminal airspace and airport surface emissions," Journal of Guidance, Control, and Dynamics, vol. 37, no. 3, pp. 789-798, 2014.

[36] M. Rosskopf, S. Lehner, and V. Gollnick, "Economic-environmental trade-offs in long-term airline fleet planning," Journal of Air Transport Management, vol. 34, pp. 109-115, 2014.

[37] V. Ho-Huu, S. Hartjes, H. Visser, and R. Curran, “An efficient application of the MOEA/D Algorithm for designing noise abatement departure trajectories," Aerospace, vol. 4, no. 4, p. 54, 2017.
[38] C. Müller, K. Kieckhäfer, and T. S. Spengler, "The influence of emission thresholds and retrofit options on airline fleet planning: an optimization approach," Energy Policy, vol. 112, pp. 242-257, 2018.

[39] R. De Neufville and A. R. Odoni, "Airport Systems: Planing, Design, and Management," in Cost-Effectiveness of Eurocontrol ATM System, McGraw-Hill, New York, NY, USA, 2004.

[40] ICAO, ICAO Annex 16 Volume II Aircraft Engine Emissions, ICAO, Montreal, Canada, 8th edition, 2014.

[41] J. Koopmann, M. Ahearn, E. Boeker, A. Hansen, and S. Hwang, "Aviation environmental design tool (AEDT) technical manual version 2a," Fuel Consumption, vol. 8, no. 98, pp. 149-158, 2014.

[42] A. Nuic, D. Poles, and V. Mouillet, "BADA: an advanced aircraft performance model for present and future ATM systems," International Journal of Adaptive Control and Signal Processing, vol. 24, no. 10, pp. 850-866, 2010.

[43] S. Alumur and B. Y. Kara, "Network hub location problems: the state of the art," European Journal of Operational Research, vol. 190, no. 1, pp. 1-21, 2008.

[44] J. F. Zhu, Airline Network Planning in Air Transportation Planning, Northwestern Polytechnical University Press, Xi'an, Shaanxi, China, 2010.

[45] China Civil Aviation Administration Development Planning Division, Air Transportation Development Indicators, "in Civil Aviation from Statistics, Civil Aviation Press, Beijing, China, 2015.

[46] M. Parsa, A. S. Nookabadi, S. D. Flapper, and Z. Atan, "Green hub-and-spoke network design for aviation industry," Journal of Cleaner Production, vol. 229, pp. 1377-1396, 2019.

[47] Y. Zhou, Y. Jiao, J. Lang et al., "Improved estimation of air pollutant emissions from landing and takeoff cycles of civil aircraft in China," Environmental Pollution, vol. 249, no. 249, pp. 463-471, 2019. 